$11,337(48 \%)$ of the women were known to of depression and loss of libido with strongly tested, and the clinical symptoms correlated have istopped taking the pill, 7,563 (32\%) were lost or withdrawn, and only 4,711 (20\%) were known to be still taking the pill at the time of the final analysis. The main reason given for stopping the pill was intercurrent morbidity (33.6\%). This was mostly depression and headaches. However, it is stated, "the report shows that only in a small fraction of these diseases is there any convincing evidence that the pill has any adverse pharmacological influence, and the justification for stopping in other circumstances must be questioned." Only 7.1\% stcpped for side effects which were unspecified.

In the C.I.F.C. trial of 797 women receiving one or more of 34 oral contraceptives over six years we found that "women found oral contraceptives so efficient and beneficial that few discontinued the method unless they had multiple complaints. These were headaches, mood changes, vein changes, irregular cycles and weight gain." The number stopping the pill within a year related closely to the number with headaches and the number whose endometnial biopsies showed prominent arterioles. For several progestogen-oestrogen combinations a critical dose level was found which produced a maximum effect on headaches and endometrial anterioles, and this peak effeot was very sensitive to small changes in either oestrogen or progestogen. In view of these findings it is odd to say that headache is unlikely to be a pharmacological side effect of the pill and that the increase is affected by excess reponting and substantial bias.

The report dismisses the studies showing a significant increase of depression and an association of progestogen use as being "less well controlled than those with a more favourable conclusion." Our finding of $28 \%$ progestogenic low-aestrogen pills and $6^{\circ}$ with the strongly oestnogenic pills was supponted by the matching changes in monoamine oxidase activity in the endometrium. ${ }^{4}$ There is now strong evidenoe $e^{5-7}$ in suppont of our earlier findings that depression and loss of libido are due to hormone and enzyme changes. In the same C.I.F.C. trial vein complaints, leg oramps, and thrombophlebitis were significantly more frequent with the combined pills containing a relanively low dose of progestogen and a high dose of oestrogen than with the other groups with changes in endometrial sinusoids. ${ }^{3}$

There are many other criticisms that could be levelled against the report, but it is important as it highlights the large numbers of conditions made worse by the pill in a short time and shows an increase in the deaths when the large number of drop-outs are taken into account. As it was supported by so much public money, it is unfontunate that the general public has been given a winong impression of what the report does show. A close look at it does not give the reassurance of the pill's advantages compared with other methods of contraception implied by the press coverage, and there is no reason to think doctors need not be on the look-out for warning symptoms of disease which can lead to irreversible changes.-I am, etc.,

New Malden, Surrey

ELLEN C. G. Grant

1 Royal College of General Practitioners, Oral Con traceptives and Health. London, Pitman Medical,

2 Grant, E. C. G., British Medical fournal, 1968, 3, 402.
4,73. 7 . C. G., British Medical fournal, 1969,

Grant, E. C. G., and Pryse-Davies, J., British

Wyatt, D. L., and Murphy, R. G., Science, 1973, 173, 916.

Coppin, A., Eccleston, E. G., and Peet. M., Aylucet, 1973, 2, 60

tions System, 1973, 1, July, p. 30 .

\section{Achalasia of the Cardia}

SIR,-Your leading anticle on this subject (8 June, p. 515) rightly stresses the impontance of early treatment. In the very early stages of the disease stripping waves may be seen in the oesophagus at a barium swallow examination which are more forceful than normal waves, but they are rendened ineffective because the distal sphincter does not relax. As the condition progresses the stripping waves diminish until eventually they may disappear. It has never been established whether the loss of stripping waves is secondary to the dilatation and obstruotion of the oesophagus or whether it is a part of the disease itself.

If the condition is treated early enough the oesophagus never dilates and is able to empty with the patient lying. It is not, perhaps, as widely known as it should be that the presence of stripping waves does not refute the diagnosis of early achalasia. -I am, etc.,

Cambridge

F. R. BERRIDGE

\section{Salaries in Occupational Medicine}

SIR,-Doctors working in occupational medicine will note that new recommended salary scales have been approved and are now published (see p. 130).

These new scales are in line with the in creases recommended for doctors in the N.H.S. by the Review Body. They are within stage three and may legally be paid by emthat the 12-month rule is observed. They do not, however, include threshold payments since these cannot be paid unless threshold agreements have been made.

Some large industries fix their doctors' salaries in discussions with the B.M.A. and these employers have, of course, been asked to make the appropriate inoreases; they have
The rules about threshold agreemen Thicated and so an explanation is included with every copy of the new salary scales (which are appended to the booklet "The Doctor in Industry" obtainable from Medical fournal, 1968, 3, 777 . ployers back-dated to 1 April 1974 provided the Secretary of the B.M.A.). The important point, however, is that doctors should try to make a threshold agreement as soon as possible because payment is lawful only if the agreement is made before the monthly cost of living figures are announced.-I am etc.

$$
\begin{array}{r}
\text { R. E. W. FISHER } \\
\text { Occupariman, } \\
\text { Octional Health Committee, B.M.A. }
\end{array}
$$

B.M.A. House,
London w.C.1

\section{Clinical Public Health Doctors and Community Medicine}

SIR,-YYour leading article (18 May, p. 348) rightly stresses the curnent uncertainty of the clinical medical officers. As more Ministry circulars are published the links of the previous clinical public health doctors with community medicine are becoming more uncertain. An alarming fact is that the Faculty of Community Medicine seems to have turned its face against all preventive clinical work as not being part of the work of the community physician.

It is obvious that Ministry and regional medical officers are totally administrative and this is largely true for the area medical officer. When the duties of the specialists in community medicine and the district community physician are considered, though there is a large administrative responsibility, the contact with the patient is potentially greater. However, Ministry teams travel the country and inform us that clinical work is no part of the role of the consultant in community medicine. There must be no reduction in preventive servioes to the patient and it is hopefully assumed that there are enough clinical medical officers left to continue this work.

To consider two illustrations of the dilemma. I submit that the community specialists in child health with no interest in clinical work will have poor advice to offer in their responsibilities to the education authorities. Similarly the specialists in community medicine (environmental health) need an up-to-date clinical knowledge to control infectious disease adequately.

It seems to me that at district and aree levels a small but significant part of the work of the community physician is clinical in content and is thus complementary to the work of the clinical doctors, who are nic lenger in "public health" but in "community midicine"-it is well to remember that many of these clinical doctors are members of the Faculty of Community Medicine. Thus the clinical preventive work should be fostered

All of us await the Court Report with interest, and 12 months to two years is a long time to wait. In the meantime clinical medical officers remain in their state of uncertainty. The school health service and other preventive clinical services are enfeebled in those industrial areas where the service is needed most. Am I too cynical in suggesting that perhaps some management expert somewhere has decided that the child health service has had its day? Personally, I do not think careful assessment of childnen is ever a waste of time and I trust that this aspect at least will be preserved in the future. However, we had better hurry and decide on the career struoture for the clinical doctors, or by the time the decision has been taken at top management level the older clinical 